\title{
PODER DE MERCADO DAS EXPORTAÇÕES DE FARELO DE SOJA: UMA ANÁLISE VIA DEMANDA RESIDUAL*
}

\author{
Daniel Arruda Coronel ${ }^{* *}$
}

Airton Lopes Amorim ${ }^{* * *}$

Marcelo José Braga ${ }^{* * * *}$

\section{Antônio Carvalho Campos ${ }^{* * * *}$}

RESUMO O objetivo deste trabalho foi verificar o poder de mercado das exportações de farelo de soja argentinas, brasileiras e americanas para a União Europeia, de janeiro de 1999 a dezembro de 2007, que é o principal mercado consumidor dessa commodity. Para isso, foi utilizada a metodologia de demanda residual. Os resultados encontrados, usando-se os métodos sistemas de equações aparentemente não relacionadas (SUR), mínimo quadrado de dois estágios (2SLS) e mínimo quadrado de três estágios (3SLS), indicaram que, embora esse segmento seja oligopolizado pelas exportações argentinas, brasileiras e americanas, a Argentina e o Brasil possuem pequeno poder de mercado.

Palavras-chave: poder de mercado; comércio internacional; farelo de soja; demanda residual

Código JEL: F12; L13

* Artigo enviado em 4 de junho de 2010 e aprovado em 3 de novembro de 2010.

** Professor Adjunto da Universidade Federal de Santa Maria e Doutor em Economia Aplicada pela Universidade Federal de Viçosa (UFV).E-mail: daniel.coronel@ufv.br

*** Doutorando em Economia Aplicada e mestre em Economia pela UFV e bolsista de doutorado do CNPq, e-mail: aimorim2007@yahoo.com.br

**** Professor associado e coordenador do Programa de Pós-graduação em Economia Aplicada da UFV e bolsista de produtividade do CNPq, e-mail: mjbraga@ufv.br

**** Professor titular do Programa de Pós-graduação em Economia Aplicada da UFV e bolsista de produtividade do CNPq, e-mail: accampos@ufv.br 


\section{MARKET POWER OF SOYMEAL EXPORTS:}

\section{AN ANALYSIS BASED ON RESIDUAL DEMAND}

ABSTRACT The objective of this paper was to verify the market power of the Argentinean, Brazilian and American exports of soymeal to the European Union, the main consumer market of this commodity. For that, the article is based on the methodology of residual demand. Using the methods seemingly unrelated regression (SUR), two-stage least squares (2SLS) and three-stage least squares (3SLS), the results indicated that, though this segment is concentrated by Argentina, Brazil and the United States, none of these countries presented market power for soymeal exports. In other words, they are not able to change soymeal prices without to decrease the exports.

Key words: market power; international trade; soymeal; residual demand 


\section{INTRODUÇÃO}

Os mercados internacionais de grande parte das commodities agrícolas possuem uma estrutura bastante complexa. Subsídios à produção agrícola, fornecidos pelos países desenvolvidos, e barreiras tarifárias e não tarifárias fazem com que esses mercados sejam caracterizados, comumente, por competição imperfeita, em menor ou maior grau.

Condições naturais favoráveis, intervenções governamentais, intermediações comerciais e acordos internacionais fazem com que algumas commodities agrícolas sejam mais vantajosamente produzidas em alguns poucos países e consumidas, posteriormente, em toda a parte do mundo. Essa situação permite que pequeno número de países ou até mesmo um único país domine as exportações no mercado internacional, potencializando o exercício do poder de mercado.

O mercado internacional de farelo de soja é um exemplo de segmento concentrado. Segundo a Food and Agriculture Organization of the United Nations (FAO, 2009), a Argentina, o Brasil e os Estados Unidos dominam o mercado internacional de farelo de soja, os quais, conjuntamente, são responsáveis por $60 \%$ das exportações dessa commodity, sendo a União Europeia o principal mercado importador.

Nos últimos anos, a Argentina vem consolidando a sua liderança nas exportações desse segmento, uma vez que os Estados Unidos aumentaram o consumo interno de farelo de soja e o Brasil vem privilegiando as exportações do grão, desde a implantação da Lei Complementar no 87, de 13 de setembro de 1996, mais conhecida como Lei Kandir, que desonerou do Imposto sobre Circulação de Mercadorias e Serviços (ICMS) as exportações de produtos in natura.

Nesse contexto, alguns trabalhos têm procurado avaliar os preços internacionais dessa commodity, seus impactos ambientais e sociais, sua estrutura competitiva e o market-share, merecendo destaque os trabalhos de Sampaio, Sampaio e Costa (2006) e Coronel et al. (2008).

Deodhar e Sheldon (1997), por exemplo, ao procurarem estimar o grau de competição imperfeita no mercado internacional de farelo de soja, usaram para tal um modelo econométrico estrutural para o período de 1966 a 1993. Esses autores concluíram que o mercado internacional de farelo de soja era perfeitamente competitivo até a entrada de firmas argentinas, em meados dos anos 1970 . 
Seguindo essa mesma temática, o presente estudo objetivou verificar a existência de poder de mercado individual dos três maiores exportadores mundiais de farelo de soja para a União Europeia, principal mercado consumidor. As principais contribuições desse trabalho ficaram por conta da atualização do período de análise, ou seja, 1999 a 2007, cobrindo, assim, um período caracterizado por importantes mudanças econômicas, principalmente no Brasil e na Argentina; da utilização de um modelo mais econômico em termos de hipóteses e dados, isto é, o modelo de demanda defasada; e da utilização de métodos econométricos mais elaborados, como mínimos quadrados de dois estágios (2LS), mínimos quadrados de três estágios (3SLS) e regressão aparentemente não relacionada (SUR), que permitiram, entre outras coisas, a comparação dos parâmetros estimados.

Os resultados sugeriram, pelo menos para as estimativas realizadas com os modelos 2SLS e 3SLS, que o mercado de farelo de soja não se comporta como um mercado de competição perfeita, uma vez que Brasil e Argentina possuem poder de alterar seus preços lucrativamente por meio da redução na produção de farelo de soja, mesmo que a magnitude desse poder seja relativamente pequena. Os resultados indicam que mudanças estruturais importantes podem ter ocorrido nesse mercado, ao longo do período em análise, as quais alteraram a estrutura deste.

O trabalho está dividido em quatro seções, além desta introdução. $\mathrm{Na}$ primeira, faz-se uma análise do mercado mundial de farelo de soja, analisando-o em face das exportações brasileiras argentinas e americanas. $\mathrm{Na}$ segunda, são apresentados e descritos os modelos Teóricos Analíticos e também se esboçam os procedimentos econométricos e os métodos de estimação; por fim, expõe-se a fonte de dados. Na terceira, os resultados obtidos são analisados e discutidos, e, finalmente, apresentadas as principais conclusões do estudo na quarta seção.

\section{O MERCADO MUNDIAL DE FARELO DE SOJA}

A Argentina, o Brasil e os Estados Unidos são os maiores exportadores de farelo de soja e, em conjunto, são responsáveis por $60 \%$ das exportações mundiais. No segmento de farelo e óleo de soja, a liderança é da Argentina. 
Apesar de ser um segmento oligopolizado, o mercado da commodity farelo de soja é menos concentrado do que o do grão e óleo, e os três países citados anteriormente são responsáveis, respectivamente, por $85 \%$ e $71 \%$ das exportações mundiais. Além disso, no segmento farelo de soja, observa-se a ausência de barreiras tarifárias e não tarifárias, as quais incidem sobre o mercado de grãos.

Em 2007, o Brasil exportou, conforme a tabela 1, cerca de 12.474 .182 toneladas de farelo, e a taxa média geométrica de crescimento, de 1999 a 2007, foi de $3,70 \%$, bem abaixo do crescimento médio anual do grão e do óleo nesse mesmo período. De acordo com Coronel, Machado e Carvalho (2009), as exportações brasileiras do complexo soja foram afetadas, significativamente, pela Lei Kandir, que desonerou as exportações de produtos in natura do ICMS, desestimulando a venda de produtos que poderiam ter maior valor agregado, como farelo e óleo. Ainda nessa perspectiva, segundo esses autores, o crescimento médio anual das exportações dessa commodity ficou muito aquém das exportações na década de 1980 .

Em 2007, a Argentina exportou 27.857.600 toneladas de farelo de soja, e a taxa média geométrica de crescimento, de 1999 a 2007, foi de 10\%. De acordo com a Secretaría de Agricultura, Ganadería, Pesca y Alimentación (SAGPyA, 2009), a Argentina, nos últimos anos, vem priorizando os mercados de farelo e óleo de soja por meio de políticas específicas.

Em 2007, os Estados Unidos exportaram 7.301.550 toneladas de farelo, e a taxa média geométrica de crescimento, de 1999 a 2007, foi de aproximada-

Tabela 1: Evolução das exportações brasileiras, argentinas e americanas de farelo de soja (em toneladas) de 1999 a 2007

\begin{tabular}{lcll}
\hline & Brasil & Argentina & Estados Unidos \\
\hline 1999 & 10.430 .878 & 13.512 .500 & 6.123 .663 \\
\hline 2000 & 9.363 .590 & 13.579 .300 & 5.936 .337 \\
\hline 2001 & 11.269 .578 & 15.166 .100 & 6.932 .023 \\
\hline 2002 & 12.517 .160 & 17.054 .200 & 5.307 .318 \\
\hline 2004 & 13.602 .158 & 19.345 .800 & 5.288 .616 \\
\hline 2005 & 14.485 .623 & 19.139 .500 & 4.089 .168 \\
\hline 2006 & 14.421 .679 & 22.641 .300 & 5.067 .978 \\
\hline Fonte: Elaborada pelos autores a partir de dados da Secex (2008). SAGPyA (2008) e USDARS (2008).
\end{tabular}

Fonte: Elaborada pelos autores a partir de dados da Secex (2008), SAGPyA (2008) e USDA/ERS (2008). 
mente 0,46\%. Conforme destacado por Coronel et al. (2008), os Estados Unidos vêm reduzindo gradativamente as exportações de farelo de soja, uma vez que esse país tem aumentado significativamente o consumo interno desse produto, como consequência da substituição de componentes de origem vegetal na fabricação de rações.

O maior importador mundial de farelo de soja, de 1999 a 2007, foi a União Europeia, com destaque para Holanda, França, Itália e Alemanha, cabendo ainda ressaltar que, desde o final da década de 1990, a Indonésia vem se configurando um promissor mercado para as exportações brasileiras, argentinas e americanas de farelo de soja.

Segundo Coronel, Machado e Carvalho (2009), quando se comparam a produção e a comercialização de farelo de soja do Brasil, Argentina e Estados Unidos, observa-se que este último apresenta vantagens tanto na produção quanto na comercialização, em relação ao Brasil e à Argentina, no que tange a menores custos de produção e armazenamento, maiores investimentos em pesquisa, infraestrutura adequada e também fortes subsídios e diversos incentivos que são oferecidos por meio da Farm Bill.

A Argentina apresenta vantagens comparativas em relação ao Brasil devido aos menores custos de transporte, à existência de melhores solos, à menor carga tributária e à facilidade no escoamento da produção (Coronel et al. 2008).

Para Mendes e Padilha Jr. (2007), o Brasil apresenta vários problemas de transporte que acarretam perda de competitividade para o país, tais como elevada deterioração das rodovias; dificuldades de acesso aos portos; ausência de planejamento e políticas de integração entre os modais; modal aquaviário subutilizado; e burocratização na regulamentação e na área tributária. Todos esses fatores colaboram para que o país tenha custos de transportes elevados, visto que perfazem $10 \%$ do produto interno bruto, enquanto nos Estados Unidos os custos não são superiores a 6\%.

Em que pesem todos os obstáculos citados anteriormente, o Brasil apresenta vantagens em relação aos Estados Unidos e à Argentina quanto à disponibilidade de área para aumentos significativos da produção, visto que somente utilizou em torno da metade da área disponível própria para plantio de soja em todo o território nacional (Coronel, Machado e Carvalho, 2009). 


\section{METODOLOGIA}

\subsection{Modelo teórico}

Do ponto de vista econômico, uma firma (ou um grupo de firmas que agem de forma coletiva) terá poder de mercado se for capaz de aumentar lucrativamente o preço de seu produto por meio da redução da quantidade produzida deste (Landes e Posner, 1981).

O poder de mercado, para um bem qualquer, é dado pela distância entre o preço recebido pela firma e o custo marginal de produção desse bem, ou seja, a capacidade de uma firma ou indústria praticar um preço acima do seu custo marginal. A medida comumente utilizada de poder de mercado é o Îndice de Lerner (Church e Ware, 2000).

O Índice de Lerner pode ser calculado diretamente quando dados adequados sobre custo marginal das firmas estão disponíveis. Entretanto, raramente essas informações podem ser encontradas. A maioria dos estudos que calculam esse índice adota o custo variável médio como uma proxy para o custo marginal, mas, como observado por Deodhar e Pandey (2006), exceto para firmas competitivas em equilíbrio de longo prazo, o custo variável médio não é uma aproximação adequada para o custo marginal.

Com o intuito de superar as dificuldades relacionadas com a mensuração do Índice de Lerner, com base em dados contábeis foram propostos alguns modelos econométricos que compõem a Nova Organização Industrial Empírica (Neio).

O modelo utilizado no presente trabalho, isto é, o modelo de demanda residual, baseado na Neio, foi desenvolvido inicialmente por Baker e Bresnahan (1988) para verificar o poder de mercado em estudos de organização Industrial e política antitruste, sendo posteriormente aperfeiçoado por Goldberg e Knetter (1999), para estudos de comércio internacional.

A hipótese fundamental da abordagem proposta por Goldberg e Knetter (1999) é de que as commodities exportadas pelos países de origem são substitutos perfeitos, enquanto as commodities produzidas por países diferentes podem ser substitutos perfeitos ou imperfeitos.

As funções de demanda do país importador pelo conjunto de produtos importados podem ser expressas da seguinte forma: 


$$
\begin{aligned}
& P^{e x}=D^{e x}\left(Q^{e x}, P^{1}, \ldots, P^{n}, Z\right), \\
& P^{k}=D^{k}\left(Q^{k}, P^{j}, P^{e x}, Z\right), \operatorname{com} j=1,2, \ldots n \text { e } j \neq k
\end{aligned}
$$

em que $P^{e x}$ é o preço de determinada commodity, exportada em unidade monetária do país de destino para determinado mercado consumidor; $Q^{e x}$, quantidade total exportada do país de origem para o país de destino; $P^{1}, \ldots, P^{n}$, preços dos seus concorrentes no mercado internacional; e $Z$, variáveis que deslocam a demanda do país importador.

Cada firma exportadora " $i$ " do país de origem maximiza o lucro da seguinte forma:

$$
\max _{q_{i}^{e x}} \prod_{i}^{e x} P^{e x} q_{i}^{e x}-e C_{i}^{e x}
$$

em que e é a taxa de câmbio e $C_{i}^{e x}$, o custo em unidades monetárias do país exportador.

A equação de maximização do lucro para o país exportador, sob a condição de custo marginal igual à receita marginal, é dada por:

$$
P^{e x}=e \cdot M C_{i}^{e x}-q_{i}^{e x} \cdot D_{1}^{e x}\left(1+\sum_{j \neq i} \frac{\partial q_{j}^{e x}}{\partial q_{i}^{e x}}\right)\left(1+\sum_{k} \frac{\partial D^{e x}}{\partial P^{k}} \cdot \frac{\partial D^{k}}{\partial P^{e x}}\right)
$$

De acordo com Goldberg e Knetter (1999), as variáveis utilizadas na equação de maximização do lucro são:

$M C_{i}^{e x}=$ custo marginal na moeda do país de origem;

$D_{1}^{e x}=$ derivada parcial da função demanda com respeito ao seu primeiro argumento;

$\theta_{i}^{e x}=$ variável que visa a captar o comportamento estratégico das firmas do país exportador; e

$\phi^{e x}=$ variável que visa a captar a interação estratégica entre as firmas do país de origem e seus concorrentes no mercado internacional.

Usando as notações descritas anteriormente, pode-se reescrever a condição de primeira ordem da seguinte maneira:

$$
P^{e x}=e \cdot M C_{i}^{e x}-q_{i}^{e x} \cdot D_{1}^{e x} \theta_{i}^{e x} \phi^{e x}
$$

Essa condição indica que a receita marginal do país exportador depende da interação estratégica das firmas do país exportador e da interação estra- 
tégica das firmas do país exportador com os seus concorrentes no mercado internacional.

Como essa equação requer dados individuais de cada firma, Goldberg e Knetter (1999) propõem que se utilizem hipóteses agregadoras, ou seja, que se interpretem os parâmetros como média ponderada das indústrias. Dessa forma, ter-se-ia a média ponderada da participação de cada firma no país de origem.

Multiplicando-se a condição de primeira ordem pela participação de cada firma no país de origem e somando-as, ter-se-ia a seguinte condição:

$$
\sum_{i} s_{i} \cdot P^{e x}=\sum_{i} s_{i} \cdot e \cdot M C_{i}^{e x}-\sum_{i} s_{i} \cdot q_{i}^{e x} \cdot D_{1}^{e x} \theta_{i}^{e x} \phi^{e x}
$$

Manipulando-se a equação anterior, levando em consideração $\sum_{i} s_{i}=1 \mathrm{e}$ $q_{i}^{e x}=S_{i} \cdot Q^{e x}$, obtém-se uma versão transformada da condição de primeira ordem:

$$
P^{e x}=e \cdot M C^{e x}-Q^{e x} \cdot D_{1}^{e x} \theta^{e x} \phi^{e x}
$$

em que

$$
M C^{e x}=\sum_{i} s_{i} \cdot M C_{i}^{e x} \text { e } \theta^{e x}=\sum_{i} s_{i}^{2} \cdot \theta_{i}^{e x}
$$

Por similaridade, obtém-se a equação de primeira ordem dos países concorrentes no comércio mundial:

$$
P^{k}=e \cdot M C^{k}-Q^{k} \cdot D_{1}^{k} \cdot \vartheta^{k} \text {, em que } \vartheta^{k}=\theta^{k} \cdot \phi^{k} \text { e } k=1,2, \ldots, n
$$

Nota-se que se obteve, até aqui, uma generalidade cujas curvas de demanda são arbitrárias, uma vez que as commodities dos países competidores podem ou não ser substitutos perfeitos. As curvas de oferta também são generalidades, cujos padrões que indicam interações estratégicas podem variar de zero, o que indicaria competição perfeita, até valores que indicariam um cartel. Além disso, também não foi feita nenhuma hipótese relacionada com o formato da curva de custos, os quais podem ser constantes ou funções das quantidades produzidas (Goldberg e Knetter, 1999). 
Para se obter a curva de demanda residual dos países exportadores, devem-se transformar as equações (1) e (4) para se obter apenas uma equação. Dessa forma, resolve-se o sistema de equação dado por (2) para os preços dos países competidores.

Segundo Goldberg e Knetter (1999), o custo marginal para o competidor $k$ será função da quantidade produzida $Q^{k}$ e um vetor de variáveis que deslocam a curva de custos $W^{k}$.

Portanto, a condição de primeira ordem pode ser escrita da seguinte forma:

$$
P^{k}=e \cdot M C^{k}\left(Q^{k}, W^{k}\right)-Q^{k} \cdot D_{1}^{k}\left(Q^{k}, P^{j}, P^{e x}, Z\right) \cdot \vartheta^{k}
$$

Após a resolução do sistema de equações definidas por (2) e (4), obtêm-se os preços das commodities dos países competidores como funções da quantidade do bem exportado $Q^{e x}$ e de variáveis que deslocam o custo e a demanda do produto (Goldberg e Knetter, 1999).

Sendo $W^{N}$ a união de todas as variáveis que deslocam os custos de cada firma, excluindo os países exportadores de interesse e a união de todos os parâmetros de conduta para $k=1,2, \ldots, n$, conforme Goldberg e Knetter (1999), obtém-se:

$$
P^{k}=P^{k^{*}}\left(Q^{e x}, W^{N}, Z, \vartheta^{N}\right), k=1,2, \ldots, n,
$$

em que $P^{k^{*}}$ é a representação da forma parcial-reduzida e $Q^{e x}$ é a variável endógena que aparece do lado direito da equação.

Ainda de acordo com Goldberg e Knetter (1999), para se obter a demanda residual do grupo exportador, devem-se substituir as expressões (5) em (1), eliminando-se o preço dos produtos competidores (1), obtendo-se:

$$
P^{e x}=D^{e x}\left(Q^{e x}, P^{1^{*}}(.), \ldots, P^{n^{*}}(.), Z\right)=D R^{e x}\left(Q^{e x}, W^{N}, Z, \vartheta^{N}\right)
$$

Nessa equação, a demanda residual é formada por três grupos de variáveis: variáveis que denotam a quantidade exportada pelo país, variáveis que deslocam a demanda e variáveis que deslocam os custos dos competidores, cuja inclinação indica a alteração da curva demanda dos países exportadores e leva em consideração a interação estratégica de todas as outras firmas do mercado, conforme Goldberg e Knetter (1999). 
Observa-se, ao comparar a equação (6) com a equação de equilíbrio da oferta do país exportador, que o modelo está identificado. Assim, na equação (3), tem-se o custo marginal do país exportador $M C^{e x}$, o qual será uma função das variáveis que deslocam a oferta específica do grupo exportador $W^{e x}$. No entanto, essas variáveis são excluídas de (6), e apenas as variáveis que deslocam o custo das firmas competidoras $W^{N}$ entram na curva de demanda residual. Essa exclusão é que permite identificar a demanda residual (Goldberg e Knetter, 1999).

De acordo com Goldberg e Knetter (1999), a taxa de câmbio entre o país exportador e o país importador é uma variável que deve ser incluída em $W^{e x}$ cujas oscilações na taxa de câmbio movem o custo relativo das exportações de um dado país exportador, sem o aumento do custo dos países competidores.

Com base nas definições e nas equações desenvolvidas até aqui, têm-se elementos para entender a relação entre a elasticidade da demanda residual e o mark-up, em que se diferencia a versão logarítmica de (6) em relação a $Q^{e x}$.

Obtém-se a elasticidade residual $\eta_{e x}$ :

$$
\eta_{e x}=\frac{\partial \ln D R^{e x}}{\partial \ln Q^{e x}}=\frac{\partial \ln D^{e x}}{\partial \ln Q^{e x}}+\sum_{k} \frac{\partial \ln D^{e x}}{\partial \ln P^{k^{*}}} \cdot \frac{\partial \ln P^{k^{*}}}{\partial \ln Q^{e x}} .
$$

As derivadas $\frac{\partial \ln P^{k^{*}}}{\partial \ln Q^{e x}}$ indicam a sensibilidade dos preços dos competidores à mudança na quantidade exportada pelos países exportadores. Nesse sentido, $\eta_{e x}$ é uma medida da elasticidade da curva de demanda residual com a qual o país exportador se defronta. De acordo com a condição de primeira ordem (3), a elasticidade $\eta_{e x}$ será igual ao mark-up $\frac{P^{e x}-M C^{e x}}{P^{e x}}$ se e somente se a curva de demanda residual coincidir com a conjectural (Goldberg e Knetter, 1999).

Segundo Baker e Bresnahan (1988), essa condição é satisfeita nos mercados de competição perfeita e de diferenciação extensiva de produtos. Nos mercados perfeitamente competitivos, o preço de determinada firma é obtido pelo preço dos competidores, cuja elasticidade da demanda residual é zero. O mark-up também é zero, visto que as firmas estabelecem que os preços devem ser iguais aos custos marginais.

Segundo esses autores, nos casos de diferenciação de produtos, a distinção entre variações conjecturais e funções de reação torna-se menos rele- 
vante, visto que o grau de substituição entre os produtos das firmas competidoras diminui, pois, se uma firma tiver poder de mercado porque seus produtos são diferentes dos demais, os aspectos relacionados à interação estratégica se tornarão relativamente menos importantes.

De acordo com Goldberg e Knetter (1999), a estimação do modelo da elasticidade da demanda residual é mais adequada na forma logarítmica, visto que os coeficientes podem ser diretamente interpretados.

Nesse sentido, a equação genérica do modelo a ser estimada é dada por:

$$
\ln P_{t}^{e x}=\lambda+\eta \ln Q_{t}^{e x}+\alpha^{\prime} \ln Z_{t}+\beta^{\prime} \ln W_{t}^{N}+\varepsilon_{t},
$$

em que:

$\varepsilon_{t}=$ termo de erro independente e identicamente distribuído;

$\alpha$ 'e $\beta^{\prime}$ = vetores de parâmetros a serem estimados;

$Z_{t}=$ variáveis que deslocam a demanda; $\mathrm{e}$

$W_{t}^{N}=$ variáveis que deslocam o custo dos $n$ competidores com os quais o grupo exportador se defronta no mercado importador de destino.

A variável $\lambda$ indica a elasticidade da demanda residual, e a existência de competição perfeita indicaria um parâmetro igual a zero, ou seja, os países exportadores se defrontariam com uma demanda perfeitamente elástica, em que o preço do produto exportado não dependeria da quantidade exportada, mas dos custos dos outros produtores. Quanto maior for o valor de $\lambda$ em valor absoluto, maior será o desvio do preço em relação ao custo marginal, e consequentemente, o poder que esse grupo exportador exerceria sobre os preços (Goldberg e Knetter, 1999).

\subsection{Modelo analítico}

De acordo com Goldberg e Knetter (1999), as variáveis que deslocam a demanda podem ser dadas por tendência no tempo, renda nominal e estoque mantido pelo país de destino. Já as variáveis que deslocam o custo dos países competidores são dadas por aquelas que incluem o preço dos insumos.

Convém destacar, segundo Goldberg e Knetter (1999), um comentário adicional sobre a taxa de câmbio, visto que esta pode ser utilizada como variável que desloca os custos. Sua vantagem está relacionada à sua volatilidade, porque ela move os custos relativos dos exportadores de determinada 
commodity, mesmo quando os fatores de custo domésticos de determinado país não tenham se movido de maneira independente dos demais.

Neste sentido, toma-se um exemplo genérico, em que as exportações de determinada commodity exportada por determinado país e de seus concorrentes países 1 e 2, respectivamente, em que as variáveis que deslocam os custos são salários e preços de matérias-primas. Isto pode ser representado da seguinte forma

$$
\begin{aligned}
& \ln P_{t}^{e x}=\lambda+\eta \ln Q_{t}^{e x}+\alpha^{\prime} \ln Z_{t}+\beta^{1} \ln \left(e_{t}^{1} \cdot L_{t}^{1}\right)+\gamma^{1} \ln \left(e_{t}^{1} \cdot M_{t}^{1}\right)+ \\
& \beta^{2} \ln \left(e_{t}^{2} \cdot L_{t}^{2}\right)+\gamma^{2} \ln \left(e_{t}^{2} \cdot M_{t}^{2}\right)+\varepsilon_{t} \cdot
\end{aligned}
$$

em que $e$ indica as taxas de câmbio dos países competidores, no presente estudo, Argentina e Estados Unidos.

Reescrevendo a equação, isolando-se os termos referentes às taxas de câmbio, tem-se o seguinte modelo que será estimado:

$$
\begin{aligned}
& \ln P_{t}^{e x}=\lambda+\eta \ln Q_{t}^{e x}+\alpha^{\prime} \ln Z_{t}+\omega^{1} \ln e_{t}^{1}+\beta^{1} \ln L_{t}^{1}+\gamma^{1} \ln M_{t}^{1}+\omega^{2} \ln e_{t}^{2}+ \\
& \beta^{2} \ln L_{t}^{2}+\gamma^{2} \ln M_{t}^{2}+\varepsilon_{t} .
\end{aligned}
$$

Por fim, vale ressaltar que a quantidade $Q^{e x}$ é endógena e, portanto, deve ser instrumentalizada. Os instrumentos podem ser variáveis que deslocam os custos do grupo de exportadores do país de interesse. De acordo com Goldberg e Knetter (1999), isso ocorre porque essas variáveis, além de terem sido excluídas da equação a ser estimada, são correlacionadas com a quantidade em função da condição de primeira ordem. Como consequência, a taxa de câmbio entre o país exportador e o mercado de destino é, em adição às demais variáveis que deslocam os custos do país exportador, uma importante candidata a instrumento.

\subsection{Procedimentos econométricos e métodos de estimação}

Neste trabalho, com o intuito de comparar os resultados, estimou-se o sistema de demandas residuais por meios de três métodos diferentes. Em primeiro lugar, estimaram-se as regressões pelo método de mínimo quadrado de dois estágios ${ }^{1}$ (2LS), que trata cada uma das equações isoladamente, corrigindo o problema de endogeneidade dos regressores por meio das variáveis instrumentais. 
Posteriormente, estimou-se o sistema de equações aparentemente não relacionadas (SUR), que pode ser visto como uma extensão de mínimos quadrados ordinários padrão (MQO), e, por fim, utilizou-se o método de mínimo quadrado de três estágios (3SLS).

De acordo com Greene (2008), o método SUR leva em consideração as possíveis correlações existentes entre os erros das diversas equações de um sistema, o que é feito por intermédio de um estimador de mínimos quadrados generalizados.

O método 3SLS, por sua vez, incorpora aspectos dos dois métodos anteriores, estimando cada uma das equações por 2SLS e, posteriormente, estimando o sistema como um todo, da mesma forma que o SUR, conforme Greene (2008).

Já o método 2SLS calcula cada equação isoladamente, enquanto o SUR e o 3SLS estimam o sistema como um todo. Assim, eles levam em consideração todas as inter-relações existentes no sistema; no entanto, vale ressaltar que a má especificação de uma equação é propagada para todo o restante do sistema (Greene, 2008).

Para examinar a presença de endogeneidade, utilizou-se, conforme Bragança (2005), o teste de Wu-Hausman, e para verificar a validade dos instrumentos, ou seja, se os instrumentos escolhidos não estão correlacionados com o termo de erro, utilizaram-se os testes de Sargan (para 2SLS) e Hansen-Sargan (para 3SLS). O software utilizado na estimação do modelo foi o Stata 10.0 .

Foram realizados, ainda, os testes de Pagan-Hall para verificar a presença ou não de heterocedasticidade; além destes, foi realizado o teste de Cumby-Huizinga para verificar a presença ou não de autocorrelação.

As estimativas de poder de mercado serão analisadas separadamente para cada um dos três maiores exportadores mundiais de farelo de soja.

\subsection{Variáveis e fonte de dados}

Neste trabalho, utilizaram-se dados mensais no período compreendido entre janeiro de 1999 e dezembro de 2007. As variáveis utilizadas no procedimento de estimação estão descritas na tabela 2 .

A quantidade exportada de farelo de soja pelo Brasil e o preço Free On Board (FOB) das exportações foram coletados do site do Sistema de Aná- 
lise das Informações de Comércio Exterior (Alice), da Secretaria de Comércio Exterior (Secex). A quantidade exportada pela Argentina, bem como o preço dessas exportações, foi obtida do site da Secretaría de Agricultura, Ganadería, Pesca y Alimentación (SAGPyA). Por fim, a quantidade e o preço das exportações dos Estados Unidos foram obtidos do site da United States Department of Agriculture (USDA)/Economic Research Service (ERS).

A taxa de câmbio nominal real/dólar foi coletada no site do Instituto de Pesquisa Econômica Aplicada (IPEA); a taxa de câmbio nominal peso/ dólar, no site da Secretaría de Agricultura, Ganadería, Pesca y Alimentación (SAGPyA); e a taxa de câmbio nominal euro/dólar, no site do gabinete de estatísticas da União Europeia (Eurostat). Também utilizou-se como variável exógena o preço do fertilizante do Brasil, da Argentina e dos Estados Unidos.

O preço dos fertilizantes do Brasil foi coletado no site do Instituto de Pesquisa Econômica Aplicada (IPEA); o da Argentina, no site do Banco Central de La República Argentina (BCRA); e o preço dos fertilizantes dos Estados Unidos, no site da United States Department of Agriculture (USDA)/Economic Research Service (ERS). Também foi utilizada uma proxy mensal do produto interno bruto (PIB) da União Europeia, as ex-

Tabela 2: Variáveis utilizadas no procedimento de estimação

\begin{tabular}{ll}
\hline Variáveis & Descrição \\
\hline PRA & Preço do farelo de soja exportado pela Argentina (em dólares) \\
\hline PRB & Preço do farelo de soja exportado pelo Brasil (em dólares) \\
\hline PREUA & Preço do farelo de soja exportado pelos Estados Unidos (em dólares) \\
\hline EXA & Quantidade de farelo de soja exportada pela Argentina (milhões de toneladas) \\
\hline EXBRA & Quantidade de farelo de soja exportada pelo Brasil (milhões de toneladas) \\
\hline EXEUA & Quantidade de farelo de soja exportada pelos Estados Unidos (milhões de toneladas) \\
\hline CPAD & Câmbio nominal peso argentino/dólar \\
\hline CRD & Câmbio nominal real/dólar \\
\hline CDE & Câmbio nominal euro/dólar \\
\hline FERA & Índice de preços de fertilizantes da Argentina, em peso argentino \\
\hline FERB & Índice de preços de fertilizantes no Brasil, em real \\
\hline FEREUA & Índice de preços de fertilizantes nos Estados Unidos, em dólar \\
\hline PPIB & $\begin{array}{l}\text { Exportações mais importações da União Europeia, em dólar, } \\
\text { como proxy mensal do PIB (em dólares) }\end{array}$ \\
\hline Fonte: Elaborada pelos autores.
\end{tabular}


portações mensais mais as importações desse bloco, que foram obtidas do site do gabinete de estatísticas da União Europeia (Eurostat).

Em todas as variáveis citadas anteriormente, foi aplicado logaritmo natural, e as equações foram especificadas da forma $\log$ - $\log$, a qual facilita a interpretação dos coeficientes, uma vez que fornece, de forma direta, a elasticidade da variável dependente das variações nas variáveis independentes. Por fim, cabe destacar que as variáveis consideradas como endógenas ao modelo são os preços das exportações de farelo de soja, bem como a quantidade exportada desse produto por cada país.

\section{ANÁLISE E DISCUSSÃO DOS RESULTADOS}

\subsection{Determinações do poder de mercado para a Argentina}

A tabela 3 apresenta as estimativas do preço das exportações de farelo de soja da Argentina para a União Europeia.

Como a quantidade exportada de farelo de soja de cada um dos países é uma variável potencialmente endógena, ela deve ser instrumentalizada antes de a equação ser estimada. Os instrumentos utilizados estão listados na tabela 3 e foram definidos da seguinte forma: instrumentos deslocadores de custos, instrumentos deslocadores de custos dos concorrentes, taxa de câmbio, instrumentos deslocadores da renda e quantidade exportada pelos concorrentes, ou seja, variáveis correlacionadas com a variável exportação e que afetam as decisões das firmas argentinas.

No que diz respeito ao ajuste dos modelos, todos apresentaram $\mathrm{R}^{2}$ ajustado com valor um valor elevado, o que indica que as variáveis independentes explicam grande parte da variabilidade da variável dependente.

A estatística de Sargan, aplicada nas estimações realizadas pelo método de mínimo quadrado de dois estágios, indicou que não se pode rejeitar a hipótese de que os instrumentos utilizados na estimação sejam válidos. Da mesma forma, o teste de Hansen-Sargan atesta para a validade dos instrumentos utilizados na estimação da equação de demanda defasada pelo método de mínimos quadrados de três estágios.

O teste de Hausman-WU indicou que não se pode rejeitar a hipótese de que a quantidade exportada seja endógena, o que justifica a instrumentalização dessa variável para estimação por mínimos quadrados de dois e três 
Tabela 3: Estimativa das exportações argentinas de farelo de soja para a União Europeia, variável dependente - preço do farelo de soja da Argentina

\begin{tabular}{|c|c|c|c|}
\hline Método de Estimação & SUR & $2 S L S$ & $3 S L S$ \\
\hline \multirow[t]{2}{*}{ Constante } & $-0,9217$ & $-0,4174$ & $-0,6013$ \\
\hline & $(0,5808)$ & $(0,7950)$ & $(0,7986)$ \\
\hline $\begin{array}{l}\text { Preço defasado do farelo de soja } \\
\text { exportado pela Argentina }\end{array}$ & $\begin{array}{l}0,8435 * * * \\
(0,0389)\end{array}$ & $\begin{array}{l}0,9514^{* * *} \\
(0,0591)\end{array}$ & $\begin{array}{l}0,9042 * * * \\
(0,0580)\end{array}$ \\
\hline \multirow[t]{2}{*}{$\begin{array}{l}\text { Quantidade exportada de farelo } \\
\text { de soja pela Argentina }\end{array}$} & 0,0065 & $0,1026 * *$ & $0,0834 * *$ \\
\hline & $(0,0060)$ & $(0,0461)$ & $(0,0420)$ \\
\hline PIB União Europeia & $\begin{array}{c}0,0209 \\
(0,0462)\end{array}$ & $\begin{array}{c}-0,0843 \\
(0,0719)\end{array}$ & $\begin{array}{c}-0,0630 \\
(0,0707)\end{array}$ \\
\hline Preço de fertilizante no Brasil & $\begin{array}{l}-0,0010 \\
(0,0329)\end{array}$ & $\begin{array}{l}-0,0927 \\
(0,0622)\end{array}$ & $\begin{array}{l}-0,0782 \\
(0,0598)\end{array}$ \\
\hline \multirow[t]{2}{*}{ Preço de fertilizante nos Estados Unidos } & $0,2808 *$ & 0,1608 & 0,2316 \\
\hline & $(0,1442)$ & $(0,2222)$ & $(0,2194)$ \\
\hline $\mathrm{R}^{2}$ ajust. & 0,8808 & 0,8331 & 0,8550 \\
\hline \multirow[t]{2}{*}{ Estatística Sargan } & - & 5,882 & - \\
\hline & & $\begin{array}{l}\text { p-valor = } \\
(0,5536)\end{array}$ & \\
\hline \multirow[t]{2}{*}{ Estatística Hansen-Sargan } & - & - & 21,043 \\
\hline & & & $\begin{array}{l}p \text {-valor = } \\
(0,1355)\end{array}$ \\
\hline \multirow[t]{2}{*}{ Estatística Hausman-WU } & - & 4,9241 & - \\
\hline & & $\begin{array}{c}\text { p-valor }= \\
(0,0287)\end{array}$ & \\
\hline
\end{tabular}

Desvios padrões entre parênteses.

* Significativo a $10 \%$; ** Significativo a $5 \%$; *** Significativo a $1 \%$.

Instrumentos: Todas as variáveis independentes mais o preço do fertilizante na Argentina, preço defasado do fertilizante na Argentina, quantidade defasada de farelo de soja exportada pela Argentina, quantidade de farelo de soja exportada pelo Brasil, quantidade de farelo de soja exportada pelos Estados Unidos, PIB defasado da União Europeia, taxa de câmbio defasada peso argentino/dólar e taxa de câmbio dólar/euro.

Fonte: Resultado da pesquisa.

estágios. Por fim, os testes de Pagan-Hall e Cumby-Huizinga indicaram ausência de heterocedasticidade e autocorrelação, respectivamente.

O coeficiente de interesse, na tabela 4 , diz respeito à variável quantidade exportada, ou seja, à elasticidade da demanda residual. O valor absoluto desse coeficiente corresponde a um valor aproximado do mark-up sobre o custo marginal. Como pode ser observado, o valor dessa elasticidade não foi estatisticamente significativo apenas no método SUR. Nos demais métodos utilizados, pôde-se constatar a significância estatística desse parâmetro, embora não tenham apresentado sinal como esperado a priori, ou seja, sinal negativo, por tratar-se de uma equação de demanda. A significância do pa- 
râmetro relacionado com a elasticidade da demanda indica que a Argentina apresenta poder de mercado, embora pequeno, para as exportações de farelo de soja para a União Europeia, ou seja, ela tem condições de influenciar os preços dessa commodity via redução do produto.

Em relação às demais variáveis estimadas, pôde-se observar que o preço defasado das exportações argentinas de farelo de soja foi importante para explicar a variabilidade no preço médio do farelo de soja, o que pode ser percebido pela sua significância. Dessa forma, o preço médio do farelo de soja, no mês atual, está relacionado com o preço praticado no mês anterior. Entretanto, o PIB da União Europeia não foi significativo para explicar as variações no preço médio das exportações de farelo de soja.

Em relação à estrutura de custos, pode-se observar, a partir da estimativa do modelo SUR, que os preços dos fertilizantes nos Estados Unidos influenciam o preço médio das exportações de farelo de soja da Argentina.

\subsection{Determinação do poder de mercado para o Brasil}

A tabela 4 apresenta as estimativas do preço das exportações de farelo de soja do Brasil para a União Europeia. Os instrumentos utilizados estão listados nessa tabela e foram definidos com base nos procedimentos utilizados na análise do poder de mercado da Argentina.

O coeficiente de determinação ajustado apresentou valor elevado, o que indica que as variáveis explicativas explicam grande parte da variabilidade no preço médio das exportações de farelo de soja brasileiro.

A estatística de Sargan, aplicada às estimações feitas pelos métodos de mínimo quadrado de dois estágios, indicou que não se pode rejeitar a hipótese de que os instrumentos utilizados na estimação sejam válidos. O teste de Hansen-Sargan também aponta para a validade dos instrumentos utilizados na estimação da equação de demanda defasada pelo método de mínimo quadrado de três estágios.

A estatística de Hausman-WU indicou que não se pode rejeitar a hipótese de que a quantidade exportada seja endógena, o que justifica, novamente, a utilização de instrumentos nos métodos 2SLS e 3SLS. Os testes de Pagan-Hall e Cumby-Huizinga também indicaram a ausência de heterocedasticidade e autocorrelação nas estimativas por 2SLS.

O coeficiente relacionado com a variável quantidade exportada, ou seja, a elasticidade da demanda residual, conforme a tabela 3 , foi significativo apenas 
Tabela 4: Estimativa das exportações brasileiras de farelo de soja para a União Europeia, variável dependente - preço do farelo de soja do Brasil

\begin{tabular}{|c|c|c|c|}
\hline Método de Estimação & SUR & 2SLS & 3SLS \\
\hline \multirow[t]{2}{*}{ Constante } & $-0,5737$ & $-2,3231 * *$ & $-0,7953$ \\
\hline & $(0,5093)$ & $(0,9391)$ & $(0,7714)$ \\
\hline $\begin{array}{l}\text { Preço defasado do farelo de soja } \\
\text { exportado pelo Brasil }\end{array}$ & $\begin{array}{l}0,8448 * * * \\
(0,0384)\end{array}$ & $\begin{array}{l}0,9283 * * * \\
(0,0486)\end{array}$ & $\begin{array}{l}0,8940 * * * \\
(0,0426)\end{array}$ \\
\hline \multicolumn{4}{|l|}{ Quantidade de farelo de soja } \\
\hline exportada pelo Brasil & $\begin{array}{c}0,0110 \\
(0,0104) \\
\end{array}$ & $\begin{array}{l}0,0879 * * \\
(0,0486) \\
\end{array}$ & $\begin{array}{c}0,0142 \\
(0,0346) \\
\end{array}$ \\
\hline PIB União Europeia & $\begin{array}{l}0,1042 * * \\
(0,0482)\end{array}$ & $\begin{array}{l}0,1578^{* *} \\
(0,0620)\end{array}$ & $\begin{array}{l}0,1074^{* *} \\
(0,0531)\end{array}$ \\
\hline Preço de fertilizante da Argentina & $\begin{array}{c}-0,0020 \\
(0,0223)\end{array}$ & $\begin{array}{l}-0,0754^{* *} \\
(0,0348)\end{array}$ & $\begin{array}{r}-0,0254 \\
(0,0286) \\
\end{array}$ \\
\hline Taxa de câmbio dólar/euro & $\begin{array}{l}-0,1383 \\
(0,0901)\end{array}$ & $\begin{array}{l}-0,3688 * * * \\
(0,1346)\end{array}$ & $\begin{array}{c}-0,2035^{*} \\
(0,1082)\end{array}$ \\
\hline $\mathrm{R}^{2}$ ajust. & 0,8927 & 0,882 & 0,8975 \\
\hline Estatística Sargan & - & $\begin{array}{c}8,994 \\
p-\text { valor }= \\
(0,3428)\end{array}$ & - \\
\hline Estatística Hansen-Sargan & - & - & $\begin{array}{l}21,043 \\
p-\text { valor }= \\
(0,1355)\end{array}$ \\
\hline Estatística Hausman-WU & - & $\begin{array}{c}3,2646 \\
p-v a l o r= \\
(0,0737)\end{array}$ & - \\
\hline \multicolumn{4}{|c|}{$\begin{array}{l}\text { Instrumentos: Todas as variáveis independentes mais o preço do fertilizante no Brasil, preço defasado do fertilizante na Argentina, } \\
\text { preço defasado do fertilizante nos Estados Unidos, taxa de câmbio real/dólar, taxa de câmbio defasada real/dólar, PIB defasado } \\
\text { da União Europeia, taxa de câmbio defasada peso argentino/dólar,quantidade defasada de farelo de soja exportada pelo Brasil, } \\
\text { quantidade de farelo de soja exportada pela Argentina. }\end{array}$} \\
\hline Fonte: Resultado da pesquisa. & & & \\
\hline
\end{tabular}

Fonte: Resultado da pesquisa.

no método 2SLS, o que indica que o Brasil apresenta poder de mercado, embora pequeno, para as exportações de farelo de soja para a União Europeia, ou seja, o país consegue influenciar os preços dessa commodity via redução do produto. Deve-se atentar que, embora esse coeficiente seja significativamente estatístico, assim como o da Argentina, não apresentou sinal como esperado $a$ priori; contudo, como o interesse focava na magnitude do parâmetro, a não obtenção do sinal esperado não invalida as inferências realizadas.

O preço defasado das exportações brasileiras de farelo de soja também foi importante para explicar a variabilidade no preço médio do farelo de 
soja, o que pode ser percebido pela sua significância nos três métodos estimados. Dessa forma, o preço médio do farelo de soja, no mês atual, está relacionado com o preço praticado no mês anterior.

Ao contrário das estimativas para a Argentina, o PIB da União Europeia foi estatisticamente significativo para explicar as variações no preço médio das exportações brasileiras de farelo de soja pelos três métodos. Além disso, apresentou sinal positivo, o que está em conformidade com a teoria econômica, indicando que um aumento no PIB da União Europeia elevaria o preço das exportações de farelo de soja brasileiras para esse bloco em $0,10 \%$, $0,15 \%$ e $0,10 \%$, respectivamente, nos modelos SUR, 2SLS e 3SLS.

As estimativas referentes às estruturas de custos, no modelo 2SLS, mostram que existe relação entre preço de fertilizantes na Argentina e preço médio do farelo de soja exportado pelo Brasil, de modo que um aumento de $1 \%$ no preço de fertilizantes na Argentina reduziria em $0,07 \%$ o preço médio das exportações brasileiras de farelo de soja.

Outra variável relacionada com a estrutura de custos dos demais países considerados na análise, que foi significativa nas estimativas, foi a taxa de câmbio dólar/euro. O sinal negativo do câmbio dólar/euro indica que, quando a taxa dólar/euro cai, ou seja, quando o dólar se valoriza em relação ao euro, os custos de produção tendem a aumentar, o que, por sua vez, acarreta preços mais elevados de farelo de soja no Brasil. Essa relação se explica porque o dólar é uma moeda internacional, e os preços dos fertilizantes são fixados em dólares.

\subsection{Determinação do poder de mercado para os Estados Unidos da América (EUA)}

Na tabela 4, podem-se observar as estimativas do preço das exportações de farelo de soja dos Estados Unidos para a União Europeia.

Os instrumentos utilizados estão listados na tabela 5 e foram definidos, conforme já salientado anteriormente neste trabalho.

O coeficiente de determinação ajustado apresentou valor elevado, o que indica que as variáveis explicativas explicam grande parte da variabilidade no preço médio das exportações de farelo de soja americana.

A estatística de Sargan, aplicada às estimações feitas pelos métodos de mínimo quadrado de dois estágios, indicou que não se pode rejeitar a hipó- 
Tabela 5: Estimativa das exportações americanas de farelo de soja para a União Europeia, variável dependente — preço do farelo de soja dos Estados Unidos

\begin{tabular}{|c|c|c|c|}
\hline Método de Estimação & SUR & $2 S L S$ & $3 S L S$ \\
\hline \multirow[t]{2}{*}{ Constante } & 0,3374 & $-0,1917$ & 0,0422 \\
\hline & $(0,5191)$ & $(0,7539)$ & $(0,6664)$ \\
\hline $\begin{array}{l}\text { Preço defasado do farelo de soja exportado pelos } \\
\text { Estados Unidos }\end{array}$ & $\begin{array}{l}0,9009 * * * \\
(0,0329)\end{array}$ & $\begin{array}{l}0,9616^{* * *} \\
(0,0450)\end{array}$ & $\begin{array}{l}0,9372 * * * \\
(0,0432)\end{array}$ \\
\hline $\begin{array}{l}\text { Quantidade de farelo de soja exportado pelos } \\
\text { Estados Unidos }\end{array}$ & $\begin{array}{c}0,0049 \\
(0,0038)\end{array}$ & $\begin{array}{c}0,0310 \\
(0,0306) \\
\end{array}$ & $\begin{array}{c}0,0179 \\
(0,0164)\end{array}$ \\
\hline PIB União Europeia & $\begin{array}{c}0,0127 \\
(0,0418)\end{array}$ & $\begin{array}{c}0,0086 \\
(0,0462)\end{array}$ & $\begin{array}{c}0,0107 \\
(0,0490)\end{array}$ \\
\hline Taxa de câmbio real/dólar & $\begin{array}{l}-0,0384 \\
(0,0295)\end{array}$ & $\begin{array}{r}-0,0586 \\
(0,0385)\end{array}$ & $\begin{array}{l}-0,0455 \\
(0,0394)\end{array}$ \\
\hline Taxa de câmbio peso argentino/dólar & $\begin{array}{l}0,0366 * * * \\
(0,0137)\end{array}$ & $\begin{array}{c}0,0643^{*} \\
(0,0384)\end{array}$ & $\begin{array}{l}0,0467 * * \\
(0,0237)\end{array}$ \\
\hline $\mathrm{R}^{2}$ ajust. & 0,8917 & 0,8743 & 0,8885 \\
\hline Estatística Sargan & - & $\begin{array}{l}1,259 \\
p-\text {-valor }= \\
(0,6756)\end{array}$ & - \\
\hline Estatística Hansen-Sargan & - & - & $\begin{array}{l}21,043 \\
p-\text { valor }= \\
(0,1355)\end{array}$ \\
\hline Estatística Hausman-WU & - & $\begin{array}{c}0,8311 \\
\text { p-valor = } \\
(0,03641)\end{array}$ & - \\
\hline
\end{tabular}

Desvios padrōes entre parênteses.

* Significativo a $10 \%$; ** Significativo a $5 \%$; *** Significativo a $1 \%$.

Instrumentos: Todas as variáveis independentes mais quantidade exportada defasada de farelo de soja exportado pelos Estados Unidos, PIB defasado da União Europeia, quantidade de farelo de soja exportada pelo Brasil, quantidade de farelo de soja exportada pela Argentina.

Fonte: Resultado da pesquisa.

tese de que os instrumentos utilizados na estimação sejam válidos. O teste de Hansen-Sargan atesta a validade dos instrumentos utilizados na estimação da equação de demanda defasada pelo método de mínimo quadrado de três estágios. A estatística Hausman-WU indicou que não se pode rejeitar a hipótese de que a quantidade exportada seja endógena, o que justifica a utilização do método de mínimo quadrado de dois estágios na estimação da equação de demanda residual. Por fim, os testes de Pagan-Hall e Cumby-Huizinga indicaram ausência de hetrocesdasticidade e autocorrelação, respectivamente.

O coeficiente relacionado à variável quantidade exportada não foi estatisticamente significativo em nenhum dos métodos utilizados, o que indica que os Estados Unidos não apresentam poder de mercado para as exportações de farelo de soja para a União Europeia. 
O presente trabalho corrobora os resultados encontrados por Pick e Park (1991), que estudaram o poder de mercado do complexo soja americano, em relação aos principais importadores, utilizando modelos da Nova Organização Industrial Empírica (Neio), e concluíram que os Estados Unidos não apresentam poder de mercado para grão, farelo e óleo de soja, ou seja, apesar da metodologia e do enfoque diferente, esse estudo também apresentou resultados similares a esta pesquisa.

O preço defasado das exportações americanas de farelo de soja também foi importante para explicar a variabilidade no preço médio do farelo de soja, o que pode ser percebido pela sua significância. Dessa forma, o preço médio do farelo de soja, no mês atual, está relacionado ao preço praticado no mês anterior.

Igualmente ao que ocorreu na Argentina, o PIB da União Europeia não foi estatisticamente significativo para explicar as variações no preço médio das exportações americanas de farelo de soja para a União Europeia.

A taxa de câmbio peso argentino/dólar apresentou significância estatística, nos três métodos estimados, para explicar o preço médio das exportações americanas de farelo de soja. Contudo, o sinal não está de acordo com o esperado, visto que um aumento na taxa de câmbio peso argentino/dólar está elevando o preço médio das exportações americanas de farelo de soja em $0,037 \%, 0,0643 \%$ e 0,0467\% respectivamente. Apesar da significância estatística, faltam elementos, na literatura, para justificar tal relação, uma vez que o peso argentino não é uma moeda com grande importância no comércio internacional, a ponto de que desvalorizações nessa moeda alterem a estrutura de custos nos Estados Unidos e elevem o preço médio das exportações de farelo de soja desse país.

As análises empíricas do mercado de farelo de soja indicaram que esse mercado tem elementos de concorrência imperfeita, ou seja, Argentina e Brasil conseguem, individualmente, alterar os preços no mercado mundial, ao reduzir a quantidade produzida.

Contudo, o poder de mercado é pequeno, visto que o farelo de soja pode ser considerado como um produto homogêneo, não havendo diferenciação de produtos, de modo que não se consegue obter ganhos lucrativos de preços pela redução ou aumento na quantidade ofertada. Além disso, outro 
fator que facilita a entrada de mais competidores nesse mercado é a não existência de barreiras tarifárias e não tarifárias.

Estudos sobre poder de mercado relacionados com farelo de soja no comércio internacional são escassos, o que dificulta a realização de análises comparativas. No entanto, os resultados encontrados neste trabalho vão ao encontro do estudo de Deodhar e Sheldon (1997), que verificaram o poder de mercado das exportações de farelo de soja argentinas, brasileiras e americanas com dados anuais, de 1966 a 1993. Nesse trabalho, os autores constataram que o poder de mercado das firmas argentinas e brasileiras era ínfimo, ou seja, quase nulo.

\section{CONCLUSÕES}

As exportações argentinas, brasileiras e americanas de farelo de soja apresentaram, de 1999 a 2007, um crescimento, tendo a Argentina apresentado um crescimento extremamente significativo, com valor médio anual de 10\%. A Argentina e os Estados Unidos têm vantagens comparativas ao Brasil, no que tange a menores custos de produção e logística, enquanto o Brasil apresenta vantagens quanto à disponibilidade de aumento da área para aumento da produção.

Em relação às análises de poder de mercado, contatou-se que esse segmento é oligopolizado pelas exportações argentinas brasileiras e americanas, e Argentina e Brasil possuem um ínfimo poder de mercado.

Os resultados deste trabalho permitem compreender a estrutura de formação de preço no segmento de farelo de soja e podem contribuir, dessa forma, para indicações de possibilidades relacionadas com implementação de políticas de preços e comerciais que visem a maior competitividade desses países nesse segmento.

A partir deste trabalho, vários outros aspectos podem ser analisados, como estudos mais avançados que vise a analisar o poder de mercado do complexo soja para verificar o poder de mercado da Argentina, Brasil e Estados Unidos para o grão e o óleo de soja, bem como análises internas no intuito de verificar quais firmas possuem poder de mercado na indústria de processamento e esmagamento de soja. 


\section{NOTA}

1. Para mais informações sobre os métodos de 2LS, 3LS e SUR, ver Johnston (1984) e Greene (2008).

\section{REFERÊNCIAS BIBLIOGRÁFICAS}

BAKER, J.; BRESNAHAN, T. Estimating the residual demand curve facing a single firm. International. Journal of Industrial Organization, n. 6, p. 283-300, 1988.

BANCO CENTRAL DE LA REPÚBLICA ARGENTINA (BCRA). Estatísticas e Indicadores. 2009. Disponível em: < http://www.bcra.gov.ar>. Acesso 10 jan. 2009.

BRAGANÇA, G. G. F. Poder de mercado via demanda residual: o café brasileiro nos EUA. In: BRAGA, M. J.; AGUIAR, D. R. D.; TEIXEIRA, E. C. T. (Eds.). Defesa da concorrência e poder de mercado no agronegócio. Viçosa: UFV, 2005.

CHURCH, J.; WARE, R. Industrial Organization: a Strategic Approach. San Francisco: McGraw-Hill, 2000.

CORONEL, D. A. et al. Exportações do complexo brasileiro de soja vantagens comparativas reveladas e orientação regional. Revista de Política Agrícola, v. XVII, p. 20-32, out./dez. 2008.

CORONEL, D. A.; MACHADO, J. A. D.; CARVAlHO, F. M. A. D. Análise da competitividade das exportações do complexo soja brasileiro de 1995 a 2006: uma abordagem de market-share. Revista de Economia Contemporânea, v. 13, p. 281-308, 2009.

DEODHAR, S. Y.; PANDEY, V. Degree of Instant Competition: Estimation of Market Power in India's Instant Coffee Market. Indian Institute of Managemente. Working Paper, n. 200610-02. Índia, 2006. Disponível em: http://www.iimahd.ernet.in/publications/data/200610-02_sdeodhar.pdf. Acesso 13 fev. 2008.

DEODHAR, S. Y.; SHELDON, I. M. Market power in the world market for soymeal exports. Journal of Agricultural Economics, v. 22, n. 1, p. 78-86, 1997.

FOOD AND AGRICULTURE ORGANIZATION OF THE UNITED NATIONS (FAO). Statistical databases. 2009. Disponível em: <http://www.fao.org >. Acesso 5 jan. 2009.

GABINETE DE ESTATÍSTICAS DA UNIÃO EUROPEIA (EUROSTAT). External Trade. 2009. Disponível em: <http://epp.eurostat.ec.europa.eu/portal/page?_pageid=0,1136217,0_ 45571464\&_dad=portal\&_schema $>$. Acesso 25 jan. 2009.

GOLDBERG, P. K.; KNETTER, M. M. Measuring the intensity of competition in exports markets. Journal of International Eeconomics, v. 47, p. 27-60, 1999.

GREENE, W. H. Econometric Analysis. 6. ed. New Jersey: Pearson Prentice Hall, 2008.

INSTITUTO DE PESQUISA ECONÔMICA APLICADA (IPEA). Base de Dados. 2009. Disponível em: <http://www.ipeadata.gov.br/ipeaweb.dll/ipeadata>. Acesso 20 jan. 2009.

JOHNSTON, J. Econometric Methods. 3. ed. Nova York: Mcgraw-Hill, 1984.

LANDES, W.; POSNER, R. Market power in antitrust cases. Harvard Law Review, n. 94, v. 5, p. 937-996, 1981. 
MENDES, J. T. G.; PADILHA JR., J. B. Agronegócio: uma abordagem econômica. São Paulo: Pearson Prentice Hall, 2007.

MINISTÉRIO DO DESENVOLIMENTO INDÚSTRIA E COMÉRCIO EXTERIOR (MIDIC). Secretaria de Comércio Exterior (Secex). 2009. Disponível em: <http://www.mdic.gov.br/sitio/ secex. php>. Acesso em: 01 fev., 2008.

PICK, D. H.; PARK, T. A. The competitive structure of US agricultural exports. American Journal of Agricultural Economics, v. 73, n. 1, p. 41-48, 1991.

SAMPAIO, L. M.B; SAMPAIO, Y.; COSTA; E. D. F. Mudanças políticas recentes e competitividade no mercado internacional de soja. Revista de Economia e Sociologia Rural, Brasília, v. 44, n. 3, p. 383-411, jul./set. 2006.

SECRETARÍA DE AGRICULTURA, GANADERÍA, PESCA Y ALIMENTACIÓN (SAGPYA). Agricultura. 2009. Disponível em: <http://www.sagpya.mecon.gov.ar>. Acesso 14 fev. 2009.

UNITED STATES DEPARTMENT OF AGRICULTURE (USDA). Foreign trade statistics. 2009. Disponível em: <http://www.fas.usda.gov/ustrade/USTExBICO.asp?QI=>. Acesso 2 fev. 2009. 
